\title{
Excess Mortality From Suicide During the Early COVID-19 Pandemic Period in Japan: A Time-Series Modeling Before the Pandemic
}

\author{
Tatsuhiko Anzai ${ }^{1}$, Keisuke Fukui ${ }^{2,3}$, Tsubasa Ito ${ }^{1}$, Yuri Ito $^{3}$, and Kunihiko Takahashi ${ }^{1}$ \\ ${ }^{1}$ Department of Biostatistics, M\&D Data Science Center, Tokyo Medical and Dental University, Tokyo, Japan \\ ${ }^{2}$ Graduate School of Advanced Science and Engineering, Hiroshima University, Hiroshima, Japan \\ ${ }^{3}$ Department of Medical Statistics, Research \& Development Center, Osaka Medical College, Osaka, Japan
}

Received September 11, 2020; accepted November 29, 2020; released online December 12, 2020

\begin{abstract}
Background: Suicide amidst the coronavirus disease (COVID-19) pandemic is an important issue. In Japan, the number of suicides in April 2020 decreased by nearly 20\% from that in 2019. To assess the impact of an infectious disease pandemic, excess mortality is often discussed. Our main purpose was evaluating excess mortality from suicide in Japan during the early pandemic period.

Methods: We used data on suicides collected by the National Police Agency of Japan until June 2020. We estimated excess mortality during the early pandemic period (March-June 2020) using a time-series model of the number of suicides before the pandemic. A quasi-Poisson model was employed for the estimation. We evaluated excess mortalities by the categories of age and sex, and by prefecture.

Results: No significant excess mortality was observed throughout the early pandemic; instead, a downward trend in the number of suicides for both sexes was noted. For males, negative values of excess mortalities below the lower bound of the $95 \%$ prediction interval were observed in April and May. All numbers of females during the period were included in the interval, and the excess mortalities in June were positive and higher than those in April and May. In Tokyo, the number of suicides was below the lower bound throughout the period.

Conclusion: Our results suggest that various changes, such as communication, and social conditions amid the early COVID-19 pandemic induced a decrease in suicides in Japan. However, continuous monitoring is needed to evaluate the long-term effects of the pandemic on suicides.
\end{abstract}

Key words: excess mortality; suicide; early COVID-19 pandemic; time series modeling

Copyright $\odot 2020$ Tatsuhiko Anzai et al. This is an open access article distributed under the terms of Creative Commons Attribution License, which permits unrestricted use, distribution, and reproduction in any medium, provided the original author and source are credited.

\section{INTRODUCTION}

During the highly contagious coronavirus disease (COVID-19) outbreak in China that spread across countries worldwide in early 2020, the risk of suicide was noted to be exacerbated. ${ }^{1}$ The COVID-19 pandemic has introduced a plethora of intense new stressors, such as working from home, temporary unemployment, and home-schooling of children, which might produce anxiety, depression, and sleep disturbances. ${ }^{2,3}$ This is suspected to be related to suicide in people globally. ${ }^{4}$ However, the statistics of the National Police Agency (NPA) in Japan showed that suicides in April fell by nearly $20 \%$ from the previous year. ${ }^{5}$

The number of suicides in Japan had fallen continuously for 10 years and dipped to an all-time low of 20,169 in 2019. However, it was the leading cause of death among people aged 10 to 39 in 2018. ${ }^{6}$ Unlike other countries, Japan is not only characterized by suicide among the elderly but also by a high incidence of suicide among middle-aged men. ${ }^{7}$ The variety of factors that affect suicide differ in terms of influence depending on age and sex. ${ }^{8-10}$ Although the NPA in Japan has summarized the number of suicides, as well as potential reasons for suicide based on suicide notes and other sources, the indirect influence of the COVID-19 pandemic on suicide might not be documented. Therefore, assessing the suicide mortality burden associated with COVID-19 remains challenging.

Excess mortality is a term used in epidemiology and public health that refers to the number of mortalities above and beyond what would be expected under "normal" conditions. ${ }^{11,12}$ Excess mortality or excess death is typically defined as the difference between the number of mortalities in a specific time period and expected number of mortalities in the same time period. ${ }^{11}$ To assess the impact of infectious diseases, such as the COVID-19 pandemic, some studies evaluated whether the observed number of mortalities deviates from the $95 \%$ prediction interval (PI) of the number. ${ }^{11,13}$ Although excess mortality is a starting point for scientists to assess the overall impact of the pandemic, excess mortality from suicide has not been assessed in Japan.

In this study, therefore, we analyzed the trend of suicides in Japan during the early COVID-19 pandemic period (March-June 
2020). We constructed a time-series model based on the number of suicides before the pandemic, considering year and month trends and unemployment rate to represent social conditions. Thereafter, we evaluated excess mortality from suicide compared with the model by sex during the pandemic. We also investigated excess mortality for each sex-age category and for each prefecture. These analyses could reveal the impact of the pandemic on suicide.

\section{METHODS}

\section{Data and materials}

We analyzed data on suicide mortalities per month collected by the NPA of Japan from January 2013 to June 2020. The data were downloaded from the official website of Ministry of Health, Labour and Welfare. ${ }^{5}$ The analysis used the monthly total number of suicides and that for each sex-age category. Age of suicide was categorized into $<20,20-29,30-39,40-49,50-59,60-69$, $70-79, \geq 80$ years old, and unknown. Provisional estimates of population ${ }^{14}$ by month in Japan for each sex-age category and unemployment rate ${ }^{15}$ for each month were downloaded from the Statistics Bureau of Japan. The monthly population by prefecture was calculated by allocating a monthly population using the composition ratio of each prefecture by year.

Since we exclusively used publicly available aggregate data in this study, formal ethical review was not required.

\section{Statistical analysis}

The number of suicides at time (month) $t, y_{t}(t=1,2, \ldots T)$ was given by the following model:

$$
\begin{gathered}
y_{t} \sim \operatorname{Poisson}\left(\mu_{t}\right) \\
\log \left(\mu_{t}\right)=\beta_{0}+\beta_{Y} \text { year }_{t}+\sum_{M=1}^{12} \beta_{M} I\left(\text { month }_{t}=M\right) \\
+\beta_{U 1} u_{t}+\beta_{U 2} u_{t-1}+\operatorname{offset}\left(\log \left(\text { pop }_{t}\right)\right)
\end{gathered}
$$

where $y e a r_{t}$ is a continuous variable as the year at time $t$, month $_{t}$ is the month at time $t, u_{t}$ and $u_{t-1}$ are the unemployment rates at time $t$ and $t-1$, and pop $_{t}$ is the population at time $t$. The parameters $\beta_{0}, \beta_{Y}, \beta_{M}(M=1,2, \ldots, 12), \beta_{U 1}$, and $\beta_{U 2}$ are coefficients to be estimated, where the monthly effect $\beta_{M}$ at time $t$ is set to 0 for $M=1$, and $I(\cdot)$ is the indicator function. We applied the quasilikelihood method for inference considering the overdispersion, assuming that the variance is $\operatorname{Var}\left(y_{t}\right)=\psi \mu_{t}$. This approach has been used in several studies assessing excess mortality. ${ }^{11-13} \mathrm{An}$ underdispersion was not considered and the classical Poisson model was applied to $y_{t}$ when $\psi$ was less than 1 . We fitted the model to $y_{t}$ by sex. Coefficients were estimated using data for the non-pandemic period from January 2013 to February 2020. We also fitted the model to the number of suicides for each sex-age category and for each prefecture. Data of unknown age category were excluded from the analysis in each sex-age category.

The predicted values of $y_{t}, \tilde{y}_{t}$, for March, April, May, and June 2020 as the pandemic period were derived from the estimated model. To obtain the $95 \%$ PI of $y_{t}$, we applied a simultaneous procedure based on Bayesian inference discussed in Gelman and Hill. ${ }^{16}$ Excess mortality from suicide was defined as $y_{t}-\tilde{y}_{t}$, and the relative difference was defined as $\left(y_{t}-\tilde{y}_{t}\right) / \tilde{y}_{t}$. All statistical analyses were performed using $\mathrm{R}$ software, version 4.0.2 ( $\mathrm{R}$ Foundation for Statistical Computing, Vienna, Austria). ${ }^{17}$

\section{RESULTS}

The number of suicides declined from 2013 for both males and females (Figure 1A and Figure 1B). The 95\% PI of our model included most observed values during the non-pandemic period; only August 2014, August 2016, and December 2017 for females were outside of the intervals. Most observations for each sex-age category were also included in the PIs (eFigure 1 and eFigure 2).

Table 1 shows excess mortality and relative differences during the pandemic period. For the total number of males, negative values of excess mortality were observed throughout the period. In April and May, the number of suicides was below the lower bound of the 95\% PI. Here, we focused on the results for each age category in males. The highest excess mortality was 16.7 in March for the 40-49-year-old age group. The highest relative difference was $15.0 \%$ in April for persons aged $\geq 80$ years. However, no observed number exceeded the upper bound of the 95\% PI. The observed numbers for the 30-39- and 40-49-yearold age groups in April, and those for 50-59- and 60-69-year-old groups in May were below the lower bound of the interval.

For the total number of females, excess mortalities in March and June were positive, but those in April and May were negative; their observed numbers were within the 95\% PI. For each age category in females, the highest excess mortality was 12.6 in June for under 20 years of age, with the highest relative difference of $94.3 \%$. Excess mortality in June was positive for all age categories except for those aged 70-79 years. The lowest relative difference was $-25.6 \%$ in April for the 20-29-year-old age group. However, all observed numbers in females were included in the $95 \%$ PI.

Results by prefecture are shown in eTable 1 . The number of suicides during the period was below the lower bound of 95\% PI in Tokyo and was observed in six prefectures, including Tokyo, in May. Excess mortality was 28 compared to 15.1 (95\% PI, 7-25) in March in Yamaguchi and 84 compared to 63.1 (95\% PI, 46-82) in June in Hyogo. The excess numbers from the upper bound of the PI were only 3 and 2 cases, respectively.

\section{DISCUSSION}

In the present study, we assessed excess mortality from suicide during the early stage of the COVID-19 pandemic in Japan. Our analysis did not observe a number of suicides that exceeded the upper bound of the 95\% PI, although some positive excess mortalities were observed. Although there were concerns that the spread of COVID-19 might lead to increases in suicides, ${ }^{18}$ our results found no significant excess mortality, but rather a downward trend in the number of suicides for both males and females during the early pandemic was noted. This decrease might have been induced by various changes, such as economic activity, communication, and social conditions under the state of emergency in Japan. For example, social isolation is thought to be associated with suicide. ${ }^{19}$ In Japan, people were encouraged to stay at home during this period and spend more time with their families. One possible reason is that staying at home may have had an influence on enhancing family connectedness and preventing suicide. ${ }^{20,21}$

Excess mortalities for the total number per month in males were below the lower bound of the $95 \%$ PI. It has been pointed out that suicide among middle-aged men in Japan was more likely to be work-related. ${ }^{6}$ Actually, in $2019,58 \%$ of workers in Japan 
(A) Male

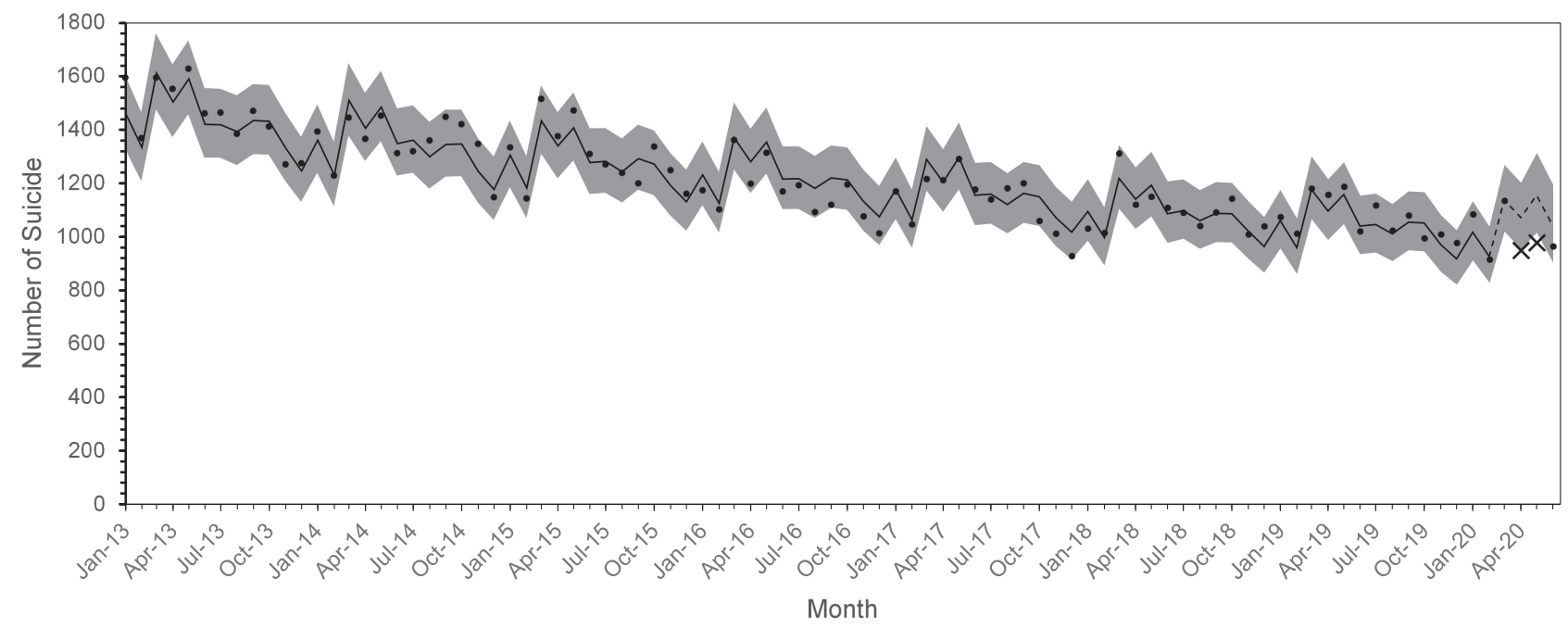

(B) Female

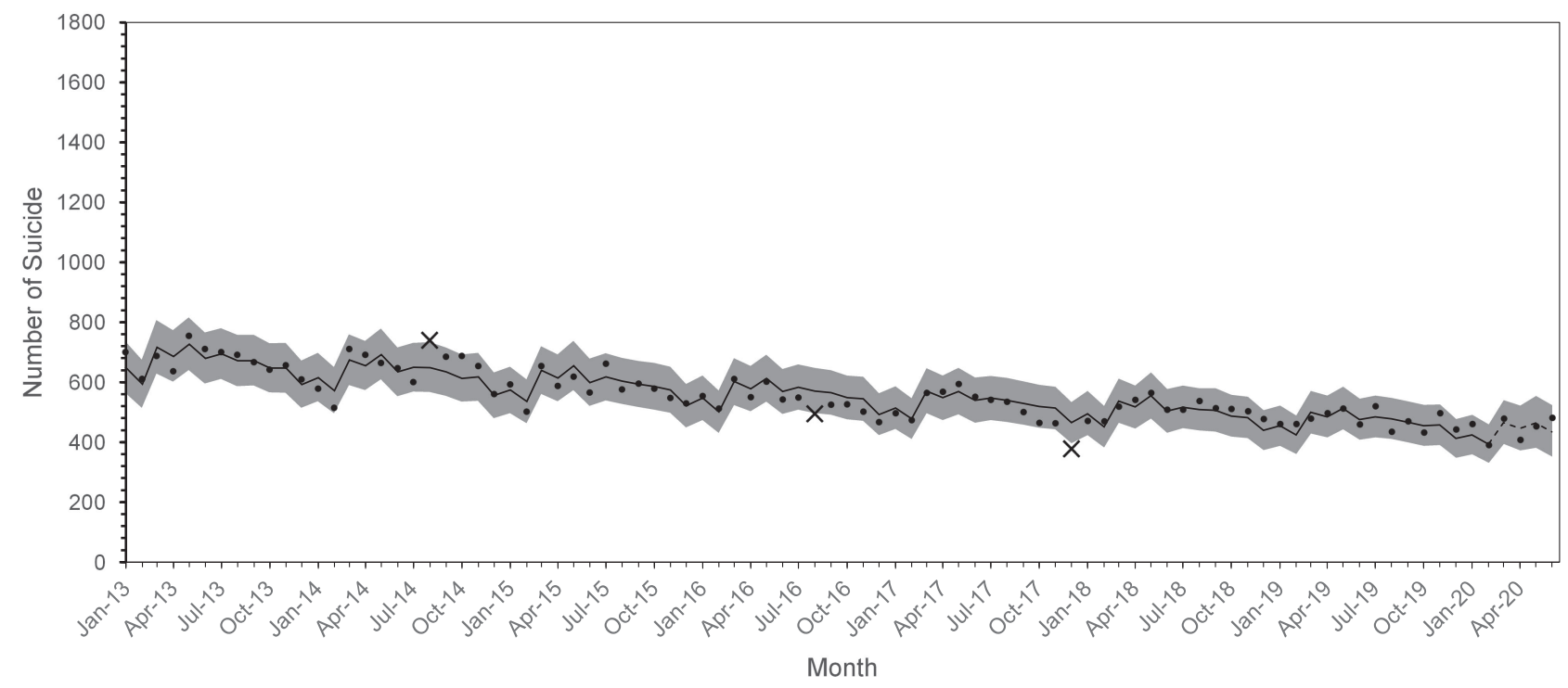

Figure 1. Monthly number of suicides and $95 \%$ prediction interval by sex, (A) male and (B) female. Dots: observed number of suicides within the $95 \%$ prediction interval; $x$ : observed number of suicides outside the $95 \%$ prediction interval; Solid line: predicted number of suicides in non-pandemic periods; Dashed line: predicted number of suicides in pandemic periods; Gray strip: $95 \%$ prediction interval for the number of suicides based on the simulated distribution.

were anxious, worried, and stressed related to their work. $^{22}$ Our results showed that negative excess mortalities were observed among the 30-69-year-old age groups amidst the early COVID-19 pandemic. One possible reason for this might be a change in their working style. For example, the percentage of telecommuting companies surged from $24.0 \%$ in March to $62.7 \%$ in April 2020. ${ }^{23}$ While telecommuting can increase stress, ${ }^{24,25}$ reducing commute times can improve the subjective wellbeing. ${ }^{26,27}$ It requires further investigations on the relationship between various style changes and stress and subjective wellbeing during the pandemic in Japan.

It has been pointed out that the months in which new semesters begin had a higher number of suicides among school children. ${ }^{28}$ The delay in the actual start of the new school year in 2020 due to school closure might have led to a negative value of excess mortalities in April for those younger than 20 years. However, those mortalities did not deviate from the PIs. This was consistent with a recent report in which no significant change was observed in suicide rates during school closure. ${ }^{29}$ On the other hand, we should note that there is some concern about the increase in family violence due to parental unemployment and that caused by increased time at home. ${ }^{30,31}$

The decrease in suicides might be temporary. Excess mortalities in June were positive and higher than those in the prior months among females. It can be inferred that the decline in suicide rates during the early pandemic months led to a gradual increase in that during later pandemics. However, the number of suicides was below the lower bound throughout the pandemic 
Anzai T, et al.

Table 1. Number of suicides, excess mortality, and relative difference by sex-age categories

\begin{tabular}{|c|c|c|c|c|c|c|c|c|c|c|}
\hline \multirow{2}{*}{$\begin{array}{l}\text { Age group } \\
\text { Month }\end{array}$} & \multicolumn{5}{|c|}{ Male } & \multicolumn{5}{|c|}{ Female } \\
\hline & $\begin{array}{l}\text { Population } \\
(\times 10,000)\end{array}$ & $\begin{array}{l}\text { Observed } \\
\text { number }\end{array}$ & $\begin{array}{l}\text { Prediction number } \\
\qquad(95 \% \mathrm{PI})^{\mathrm{a}}\end{array}$ & $\begin{array}{l}\text { Excess } \\
\text { mortality }\end{array}$ & $\begin{array}{c}\text { Relative } \\
\text { difference (\%) }\end{array}$ & $\begin{array}{l}\text { Population } \\
(\times 10,000)\end{array}$ & $\begin{array}{c}\text { Observed } \\
\text { number }\end{array}$ & $\begin{array}{l}\text { Prediction number } \\
(95 \% \mathrm{PI})^{\mathrm{a}}\end{array}$ & $\begin{array}{l}\text { Excess } \\
\text { mortality }\end{array}$ & $\begin{array}{c}\text { Relative } \\
\text { difference }(\%)\end{array}$ \\
\hline \multicolumn{11}{|l|}{ Total } \\
\hline March & 6,131 & 1,133 & $1,138.7(1019,1265)$ & -5.7 & -0.5 & 6,464 & 480 & $465.1(396,541)$ & 14.9 & 3.2 \\
\hline April & 6,131 & $946^{\mathrm{b}}$ & $1,072.4(951,1199)$ & -126.4 & -11.8 & 6,465 & 410 & $445.9(374,523)$ & -35.9 & -8.0 \\
\hline May & 6,128 & $976^{\mathrm{b}}$ & $1,155.2(1014,1309)$ & -179.2 & -15.5 & 6,462 & 455 & $464.3(383,555)$ & -9.3 & -2.0 \\
\hline June & 6,129 & 962 & $1,041.6(903,1192)$ & -79.6 & -7.6 & 6,464 & 483 & $433.9(353,524)$ & 49.1 & 11.3 \\
\hline \multicolumn{11}{|c|}{ Under 20 years old } \\
\hline March & 1,071 & 26 & $26.2(16,39)$ & -0.2 & -0.6 & 1,019 & 22 & $16.7(8,29)$ & 5.3 & 31.6 \\
\hline April & 1,071 & 27 & $37.4(23,54)$ & -10.4 & -27.9 & 1,018 & 15 & $17.3(7,31)$ & -2.3 & -13.2 \\
\hline May & 1,069 & 32 & $31.4(18,49)$ & 0.6 & 1.9 & 1,018 & 13 & $17.0(7,33)$ & -4.0 & -23.7 \\
\hline June & 1,067 & 36 & $32.3(18,52)$ & 3.7 & 11.5 & 1,016 & 26 & $13.4(4,28)$ & 12.6 & 94.3 \\
\hline \multicolumn{11}{|c|}{ 20-29 years old } \\
\hline March & 652 & 127 & $126.1(98,157)$ & 0.9 & 0.7 & 610 & 53 & $52.7(34,75)$ & 0.3 & 0.6 \\
\hline April & 654 & 115 & $113.9(87,145)$ & 1.1 & 0.9 & 612 & 37 & $49.7(31,73)$ & -12.7 & -25.6 \\
\hline May & 654 & 112 & $116.5(86,153)$ & -4.5 & -3.8 & 613 & 45 & $45.5(26,71)$ & -0.5 & -1.1 \\
\hline June & 655 & 98 & $102.9(74,138)$ & -4.9 & -4.7 & 613 & 53 & $47.4(27,75)$ & 5.6 & 11.9 \\
\hline \multicolumn{11}{|c|}{ 30-39 years old } \\
\hline March & 720 & 150 & $143.7(114,176)$ & 6.3 & 4.4 & 696 & 49 & $45.2(30,63)$ & 3.8 & 8.5 \\
\hline April & 720 & $101^{\mathrm{b}}$ & $132.9(103,166)$ & -31.9 & -24.0 & 694 & 35 & $39.5(25,57)$ & -4.5 & -11.5 \\
\hline May & 718 & 144 & $142.0(108,181)$ & 2.0 & 1.4 & 692 & 50 & $43.5(27,65)$ & 6.5 & 14.9 \\
\hline June & 717 & 123 & $118.7(88,155)$ & 4.3 & 3.6 & 692 & 48 & $38.3(22,59)$ & 9.7 & 25.4 \\
\hline \multicolumn{11}{|c|}{$40-49$ years old } \\
\hline March & 932 & 216 & $199.3(163,239)$ & 16.7 & 8.4 & 909 & 75 & $68.6(51,89)$ & 6.4 & 9.4 \\
\hline April & 929 & $135^{\mathrm{b}}$ & $187.1(151,228)$ & -52.1 & -27.8 & 907 & 64 & $63.8(46,84)$ & 0.2 & 0.2 \\
\hline May & 927 & 166 & $198.8(157,247)$ & -32.8 & -16.5 & 905 & 58 & $68.4(48,93)$ & -10.4 & -15.2 \\
\hline June & 926 & 155 & $178.5(137,226)$ & -23.5 & -13.1 & 904 & 75 & $65.4(45,90)$ & 9.6 & 14.6 \\
\hline \multicolumn{11}{|c|}{$50-59$ years old } \\
\hline March & 821 & 197 & $214.7(181,251)$ & -17.7 & -8.3 & 817 & 75 & $71.6(54,92)$ & 3.4 & 4.8 \\
\hline April & 822 & 160 & $188.9(155,225)$ & -28.9 & -15.3 & 817 & 59 & $66.2(48,87)$ & -7.2 & -10.8 \\
\hline May & 823 & $142^{\mathrm{b}}$ & $203.3(164,247)$ & -61.3 & -30.1 & 819 & 62 & $69.3(49,93)$ & -7.3 & -10.6 \\
\hline June & 825 & 150 & $188.2(150,232)$ & -38.2 & -20.3 & 820 & 63 & $61.3(42,85)$ & 1.7 & 2.8 \\
\hline \multicolumn{11}{|c|}{$60-69$ years old } \\
\hline March & 778 & 163 & $169.1(136,206)$ & -6.1 & -3.6 & 814 & 73 & $60.7(44,79)$ & 12.3 & 20.3 \\
\hline April & 776 & 152 & $158.7(125,196)$ & -6.7 & -4.2 & 812 & 67 & $58.8(42,78)$ & 8.2 & 13.9 \\
\hline May & 775 & $123^{\mathrm{b}}$ & $185.0(144,232)$ & -62.0 & -33.5 & 810 & 69 & $61.2(43,83)$ & 7.8 & 12.8 \\
\hline June & 774 & 136 & $159.5(120,205)$ & -23.5 & -14.7 & 809 & 64 & $55.1(37,76)$ & 8.9 & 16.1 \\
\hline \multicolumn{11}{|c|}{ 70-79 years old } \\
\hline March & 744 & 149 & $154.8(121,192)$ & -5.8 & -3.7 & 870 & 67 & $84.6(62,111)$ & -17.6 & -20.8 \\
\hline April & 744 & 138 & $150.2(115,190)$ & -12.2 & -8.1 & 871 & 84 & $88.7(64,117)$ & -4.7 & -5.3 \\
\hline May & 746 & 148 & $164.0(123,212)$ & -16.0 & -9.8 & 872 & 85 & $94.6(66,130)$ & -9.6 & -10.2 \\
\hline June & 747 & 157 & $151.6(111,200)$ & 5.4 & 3.5 & 874 & 83 & $85.8(58,120)$ & -2.8 & -3.3 \\
\hline \multicolumn{11}{|c|}{ Over 80 years old } \\
\hline March & 412 & 102 & $94.7(70,123)$ & 7.3 & 7.7 & 730 & 63 & $66.1(49,86)$ & -3.1 & -4.7 \\
\hline April & 415 & 112 & $97.4(71,128)$ & 14.6 & 15.0 & 732 & 49 & $62.9(45,83)$ & -13.9 & -22.1 \\
\hline May & 416 & 104 & $104.7(74,142)$ & -0.7 & -0.7 & 733 & 72 & $63.0(44,86)$ & 9.0 & 14.2 \\
\hline June & 417 & 104 & $102.9(71,142)$ & 1.1 & 1.1 & 734 & 71 & $66.4(46,91)$ & 4.6 & 7.0 \\
\hline
\end{tabular}

PI, prediction interval.

${ }^{\text {a } 95 \%}$ prediction interval based on the 2.5th and 97.5th percentile of simulated distribution.

${ }^{\mathrm{b}}$ Observed number deviated by $95 \%$ prediction interval.

period in Tokyo. These tendencies should monitored and updated. For example, under the COVID-19 pandemic, the longterm effects of economic issues, unemployment, and business bankruptcy may exacerbate suicide. ${ }^{32}$

There are many factors associated with the number of suicides, including medical and psychiatric profiles, ${ }^{4}$ divorce rates,${ }^{33}$ and monthly average temperature. ${ }^{34}$ Although we employed only unemployment rates with the year and month in our model, most observations were included in the PI throughout the nonpandemic period. That is, our model could provide an expected number under "normal" conditions. However, unemployment must be affected by the pandemic. The rate was $2.9 \%$ in May, which was the maximum during the pandemic period, while it was $2.4 \%$ in February 2020. To check the sensitivity of our results, we estimated $\tilde{y}_{t}$ as the pandemic period from the model by substituting $2.4 \%$ for the unemployment rate instead of the actual values after March 2020. We obtained consistent results in which there were no significant excess mortalities during this period as deviating from the $95 \%$ PI.

This study has several limitations. We could not identify the factors that reduced the number of suicides during the pandemic period. It is important to investigate the factors that prevent 
suicide in the future research. This study evaluated excess mortality only for the early pandemic period; however, the COVID-19 pandemic could affect suicide for a long time. Thus, continuous monitoring and evaluation is needed.

Despite the limitations of this study, our analysis could assess excess mortality from suicide during the early COVID-19 pandemic period in Japan. This approach could be applied not only to suicide but also for other causes of mortality to clarify the impacts of the pandemic. The findings of this study can help in the advancement of future research in preventive public health.

\section{ACKNOWLEDGEMENTS}

Conflicts of interest: None declared.

\section{APPENDIX A. SUPPLEMENTARY DATA}

Supplementary data related to this article can be found at https:// doi.org/10.2188/jea.JE20200443.

\section{REFERENCES}

1. Sher L. COVID-19, anxiety, sleep disturbances and suicide. Sleep Med. 2020;70:124.

2. Brown S, Schuman DL. Suicide in the time of COVID-19: a perfect storm. J Rural Heal. 2020.

3. Kawohl W, Nordt C. COVID-19, unemployment, and suicide. Lancet Psychiatry. 2020;7(5):389-390.

4. Shigemura J, Ursano RJ, Morganstein JC, Kurosawa M, Benedek DM. Public responses to the novel 2019 coronavirus $(2019-\mathrm{nCoV})$ in Japan: mental health consequences and target populations. Psychiatry Clin Neurosci. 2020;74(4):281-282.

5. Ministry of Health Labour and Welfare. Suicide statistics: basic information on suicide by region. https://www.mhlw.go.jp/stf/ seisakunitsuite/bunya/0000140901.html; 2020. Accessed 09.07.20.

6. Ministry of Health Labour and Welfare. White Paper on Children and Young People. Ministry of Health, Labour and Welfare; 2019.

7. Chiles JA, Strosahl KD, Roberts LW. Clinical Manual for the Assessment and Treatment of Suicidal Patients Second Edition. Am Psychiatric Association Pub; 2018.

8. Awata S, Seki T, Koizumi Y, et al. Factors associated with suicidal ideation in an elderly urban Japanese population: a communitybased, cross-sectional study. Psychiatry Clin Neurosci. 2005;59(3): 327-336.

9. Scocco P, De Leo D. One-year prevalence of death thoughts, suicide ideation and behaviours in an elderly population. Int $J$ Geriatr Psychiatry. 2002;17(9):842-846.

10. Murphy GE. Why women are less likely than men to commit suicide. Compr Psychiatry. 1998;39(4):165-175.

11. Vestergaard LS, Nielsen J, Richter L, et al; ECDC Public Health Emergency Team for COVID-19. Excess all-cause mortality during the COVID-19 pandemic in Europe - preliminary pooled estimates from the EuroMOMO network, March to April 2020. Euro Surveill. 2020;25(26):2001214.

12. Liu XX, Qin G, Li X, et al. Excess mortality associated with influenza after the $2009 \mathrm{H} 1 \mathrm{~N} 1$ pandemic in a subtropical city in China, 2010-2015. Int J Infect Dis. 2017;57:54-60.

13. Farrington CP, Andrews NJ, Beale AD, Catchpole MA. A statistical algorithm for the early detection of outbreaks of infectious disease.
J R Stat Soc Ser A Stat Soc. 1996;159(3):547.

14. Statistics Bureau of Japan. Monthly Report on Current Population Estimates. Statistics Bureau of Japan; 2020.

15. Statistics Bureau of Japan. Labour Force Survey. https://www. stat.go.jp/data/roudou/sokuhou/tsuki/index.html; 2020. Accessed 09.07.20.

16. Gelman A, Hill J. Data Analysis Using Regression and Multilevel/ Hierarchical Models. Cambridge University Press; 2007.

17. R Core Team. R: a language and environment for statistical computing. R Foundation for Statistical Computing, Vienna, Austria. https://www.r-project.org/; 2020. Accessed 09.07.20.

18. Gunnell D, Appleby L, Arensman E, et al; COVID-19 Suicide Prevention Research Collaboration. Suicide risk and prevention during the COVID-19 pandemic. Lancet Psychiatry. 2020;7:468471.

19. World Health Organization. Preventing Suicide: A Global Imperative. World Health Organization; 2014.

20. Purcell B, Heisel MJ, Speice J, Franus N, Conwell Y, Duberstein PR. Family connectedness moderates the association between living alone and suicide ideation in a clinical sample of adults 50 years and older. Am J Geriatr Psychiatry. 2012;20(8):717-723.

21. Gunn JF 3rd, Goldstein SE, Gager CT. A longitudinal examination of social connectedness and suicidal thoughts and behaviors among adolescents. Child Adolesc Ment Health. 2018;23(4):341-350.

22. Ministry of Health Labour and Welfare. Special Survey on Industrial Safety and Health. Ministry of Health Labour and Welfare; 2019.

23. Toyo Metropolitan Government. Results of the urgent survey about telework introduction rate. https://www.metro.tokyo.lg.jp/tosei/ hodohappyo/press/2020/05/12/10.html; 2020. Accessed 09.07.20.

24. Hartig T, Kylin C, Johansson G. The telework tradeoff: stress mitigation vs constrained restoration. Appl Psychol. 2007;56(2): 231-253.

25. Song Y, Gao J. Does telework stress employees out? A study on working at home and subjective well-being for wage/salary workers. J Happiness Stud. 2020;21:2649-2668.

26. Wener RE, Evans GW, Phillips D, Nadler N. Running for the 7:45: the effects of public transit improvements on commuter stress. Transportation (Amst). 2003;30(2):203-220.

27. Roberts J, Hodgson R, Dolan P. "It's driving her mad": gender differences in the effects of commuting on psychological health. $J$ Health Econ. 2011;30(5):1064-1076.

28. Matsubayashi T, Ueda M, Yoshikawa K. School and seasonality in youth suicide: evidence from Japan. J Epidemiol Community Health. 2016;70:1122-1127.

29. Isumi A, Doi S, Yamaoka Y, Takahashi K, Fujiwara T. Do suicide rates in children and adolescents change during school closure in Japan? The acute effect of the first wave of COVID-19 pandemic on child and adolescent mental health. Child Abuse Negl. Published online 2020:104680.

30. Campbell AM. An increasing risk of family violence during the Covid-19 pandemic: strengthening community collaborations to save lives. Forensic Sci Int Reports. 2020;2:100089.

31. Fegert JM, Vitiello B, Plener PL, Clemens V. Challenges and burden of the Coronavirus 2019 (COVID-19) pandemic for child and adolescent mental health: a narrative review to highlight clinical and research needs in the acute phase and the long return to normality. Child Adolesc Psychiatry Ment Health. 2020;14(1):20.

32. Sher L. The impact of the COVID-19 pandemic on suicide rates. QJM An Int J Med. 2020;113(10):707-712.

33. Trovato F. A longitudinal analysis of divorce and suicide in Canada. J Marriage Fam. 1987;49(1):193.

34. Burke M, González F, Baylis P, et al. Higher temperatures increase suicide rates in the United States and Mexico. Nat Clim Chang. 2018;8(8):723-729. 